$15^{\text {th }}$ International Conference on

AEROSPACE SCIENCES \& AVIATION TECHNOLOGY,

ASAT - 15 - May 28 - 30, 2013, Email: asat@mtc.edu.eg,

Military Technical College, Kobry Elkobbah, Cairo, Egypt,

Tel: +(202) $24025292-24036138$, Fax: + +(202) 22621908

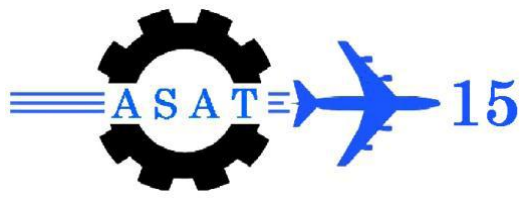

\title{
Effect of Reinforcement Ratio and Distribution on Penetration Resistance of Reinforced Concrete Panels: Numerical Simulation
}

\begin{abstract}
\{A. K. Taha and M. S. Amin $\}^{*}$
Abstract: Reinforced concrete protective layers of fortified structures are considered key points in resisting missiles penetration. Ferrocement is a highly versatile form of concrete reinforced with wire mesh reinforced in two directions. This type of reinforcement provides isotropic properties in two directions, high tensile strength, and high modulus of rupture. It also results in larger bond forces and reduces crack spacing and width compared to conventional reinforced concrete. Accordingly, concrete panels $(550$ x 550 x $300 \mathrm{~mm})$ are reinforced with expanded steel mesh instead of the conventional steel bars and tested through numerical simulation to study the parameters affecting penetration resistance. A Nonlinear three-dimensional hydrocode numerical simulation was carried out using AUTODYN 3D, which is an extensive code dealing with penetration problems. In the simulation, steel ogivenose projectile with a diameter of $23 \mathrm{~mm}$ is fired against concrete panels with striking velocity $990 \mathrm{~m} / \mathrm{s}$. Twelve numerical tests were carried out to study the parameters that significantly affect the penetration resistance of reinforced concrete panels. The parameters included are the reinforcement ratio; reinforcement position; and reinforcement distribution. The results showed that using the ferrocement wired mesh decreases the size of damage in the front and rear face of the panels. Increasing the reinforcement ratio has insignificant impact on the penetration resistance while the position and the distribution pattern of reinforcement proved to relatively enhance the penetration resistance.
\end{abstract}

Keywords: Concrete panels; ferrocement; penetration resistance; hydrocodes; steel projectile.

\section{Introduction}

The behaviour of concrete differs in dynamic loading compared to static loading. Under severe loading, when a projectile hit a concrete target, the concrete will crush and crack. The pressure at the front of the nose of the projectile is several times higher than the static uniaxial strength of concrete with an increase in the lateral pressure. Under the nose of the missile, concrete is exposed to confining pressure and behaves plastically, dissipating a large amount of energy. Since concrete is very weak in tension, the tensile wave obtained when the compressive wave hits the backside of the wall may cause scabbing at the backside, and cracking in the lateral direction[1].

Several researcher conducted experimental researches aiming to develop empirical formula that can predict the penetration depth in concrete panels caused by high speed ogive-nose projectile. An analytic/empirical study was carried out to develop an empirical model that

* Egyptian Armed Forces, Egypt. 
predicted the penetration depth of multiple impacts into concrete targets. Using the multiple impact penetration and crater formation data, a single impact penetration model was extended to account for the degradation of the target strength with each subsequent impact [2\&3]. The ballistic penetration experiments, conducted on concrete target - fragment steel projectile, show the linear dependence of the penetration depth on the striking velocity of the projectile. For the impact velocities between 300 and $1400 \mathrm{~m} / \mathrm{s}$ post-test observation of the targets showed that the fragment penetration leads to the crater formation [4].

The penetration/perforation process of reinforced concrete includes initial cratering, tunneling and rear cratering (shear plugging). Different from plain concrete in which the strength mainly dominates its ability of resisting penetration, reinforced concrete may be influenced by both the concrete strength and the amount of reinforcement. Penetration tests were carried out on regular strength concrete (RSC) and on high strength concrete (HSC) panels with different reinforcement types [5, $6 \& 7]$. The results showed that as the concrete strength increased from normal-strength to high-strength, energy absorption capacity and critical velocity of perforation increased. Different types of reinforcement and careful detailing can enhance the barrier's performance under impact, mainly by limiting the damaged area. It also, show that the concrete panels with closely spaced but small diameter wires, that had a relatively low reinforcement ratio, were less efficient against penetration or front face spalling, yet, relative to their low reinforcement ratio, they showed an enhanced resistance against perforation and scabbing.

Ferrocement is a highly versatile form of concrete reinforced with wire mesh [8]. In ferrocement mesh-reinforcing systems is used as layers of continuous expanded steel mesh. This form of reinforcement enables reinforcing in two directions; therefore, it has homogenous-isotropic properties in two directions and high reinforcement ratio. the average crack spacing decreases with increasing specific surface for both tension and flexure. However, other factors, such as the geometry of the reinforcement, also influence crack development. The average crack spacing corresponds closely to the transverse wire spacing, and the average crack width reduces as this spacing decreases. The relationship between maximum crack width or average crack width and steel stress in the extreme tensile layer of reinforcement shows that the steel stresses and crack widths in ferrocement are substantially smaller than in conventionally reinforced concrete.

Ferrocement is able to absorb a large amount of energy during fracture under dynamic loading. This is thought to be due to the substantial energy requirement to de-bond and pull out or yield and fracture the expanded steel mesh as the cracks open at high loading rates. The improvements in impact resistance with the inclusion of expanded steel mesh vary widely and depend to a large extent on the energy and velocity of the impacting mass, the size of specimen and rigidity of supports, the type of test, and even the definition of failure [9\&10].

To study the behaviour of concrete under the effect of projectile penetration, many experiments should be conducted, which are relatively expensive. The development of faster and cheaper computing software allowed numerical simulation to play a more dominant role in predicting complex interaction of projectile with concrete. A Nonlinear three-dimensional hydrocode numerical simulation was carried out using AUTODYN 3D [11 ], which is an extensive code dealing with penetration problems. In the simulation, steel ogive-nose projectile with a diameter of $23 \mathrm{~mm}$ is fired against concrete panels with striking velocity 990 $\mathrm{m} / \mathrm{s}$. Twelve numerical tests were carried out to study the parameters that significantly affect the penetration resistance of reinforced concrete panels. The parameters included are the reinforcement ratio; reinforcement position; and reinforcement distribution. The results 
showed that using the ferrocement wired mesh decreases the size of damage in the front and rear face of the panels. Increasing the reinforcement ratio has insignificant impact on the penetration resistance while the position and the distribution pattern of reinforcement proved to relatively enhance the penetration resistance.

\section{Numerical Simulation Planning and Objectives}

A preliminary design of the reinforced concrete panels is carried out to identify the strength and concrete dimensions as well as the proper reinforcement ratio. The design procedure is made using the already existing empirical formulae developed for penetration resistance [12]. The ferrocement reinforced concrete panel dimensions are set to $(550 \times 550 \times 300 \mathrm{~mm})$ for steel blunt-nose projectile type, $23 \mathrm{~mm}$ in diameter and a mass of 175 grams. Twelve numerical simulation tests were planned for varying reinforcement ratio and reinforcement positioning for different concrete panels as listed in Table 1. The main objectives would include the study of:

- The effect of reinforcement ratio on the penetration resistance.

- The influence of steel mesh distribution along the panel thickness.

- The effect of steel mesh thickness on the penetration resistance.

In order to achieve these objectives, numerical simulations are planned as follows:-

Numerical simulations named ( $\mathrm{T} 1$ - T6) were performed to study the influence of reinforcement ratio on the penetration resistance of the reinforced concrete panels.

Based on the results acquired in the previous step, the positioning of the optimum reinforcement ratio through the thickness of the concrete panel is investigated in two numerical simulations (TS7 \& T7). In (TS7) the reinforcement ratio of (T4: 1.5\%) is distributed equally spaced through the whole thickness of the panel while, in (T7), the same reinforcement ratio is distributed equally spaced through the rear half of the thickness of the concrete panel.

To study the effect of the blockage area on the penetration resistance of the concrete panels, numerical simulation (T9) is carried out. In this test the steel mesh thickness is set to $3 \mathrm{~mm}$ with opening size equal to $16 \times 38 \mathrm{~mm}$. The results are then compared to the results acquired from test (T7) that has the same reinforcement ratio and distribution. In (T7) the steel mesh thickness is set to $5 \mathrm{~mm}$ with opening size equal to $30 \times 90 \mathrm{~mm}$.

The parametric studies carried out in step 2 and step 3 mentioned above are then repeated for a different reinforcement ratio. In (T8) the reinforcement ratio of (T6:3\%) is distributed equally spaced through the whole thickness of the panel while, in (TS8), the same reinforcement ratio is distributed equally spaced through the rear half of the thickness of the concrete panel.

To study the effect of the blockage area on the penetration resistance of concrete panel T6 (3\%), numerical simulation (T10) is carried out. In this test the steel mesh thickness is set to $3 \mathrm{~mm}$ with opening size equal to $16 \times 38 \mathrm{~mm}$. The results are then compared to the results acquired from test (T8) that has the same reinforcement ratio and distribution. In (T8) the steel mesh thickness is set to $5 \mathrm{~mm}$ with opening size equal to $30 \times 90 \mathrm{~mm}$. 
Table 1. Numerical simulation tests details

\begin{tabular}{|c|c|c|c|c|}
\hline No. & Test & $\begin{array}{l}\text { Meshes number } \\
\& \text { size }(\mathrm{mm})\end{array}$ & Reinf. ratio & Reinforcement Position \\
\hline 1 & $\mathrm{~T} 1$ & $1 \mathrm{mesh} \phi 3 \mathrm{~mm}$ & $0.37 \%$ & Rear face \\
\hline 2 & $\mathrm{~T} 2$ & $1 \mathrm{mesh} \phi 5 \mathrm{~mm}$ & $0.56 \%$ & Rear face \\
\hline 3 & T 3 & $2 \mathrm{mesh} \phi 5 \mathrm{~mm}$ & $0.75 \%$ & Rear face \\
\hline 4 & $\mathrm{~T} 4$ & $4 \mathrm{mesh} \phi 5 \mathrm{~mm}$ & $1.5 \%$ & Rear face \\
\hline 5 & T5 & $6 \mathrm{mesh} \phi 5 \mathrm{~mm}$ & $2.25 \%$ & Rear face \\
\hline 6 & T6 & $8 \mathrm{mesh} \phi 5 \mathrm{~mm}$ & $3 \%$ & Rear face \\
\hline 7 & $\mathrm{~T} 7$ & $4 \mathrm{mesh} \phi 5 \mathrm{~mm}$ & $1.5 \%$ & $\begin{array}{l}\text { Equally distributed in the rear half of the } \\
\text { specimen }\end{array}$ \\
\hline 8 & TS7 & 4 mesh $\phi 5 \mathrm{~mm}$ & $1.5 \%$ & Equally distributed in the whole specimen \\
\hline 9 & T8 & $8 \mathrm{mesh} \phi 5 \mathrm{~mm}$ & $3 \%$ & Equally distributed in the whole specimen \\
\hline 10 & TS8 & $8 \mathrm{mesh} \phi 5 \mathrm{~mm}$ & $3 \%$ & Equally distributed in half of the specimen \\
\hline 11 & T9 & $6 \mathrm{mesh} \phi 3 \mathrm{~mm}$ & $1.5 \%$ & Equally distributed in rear half of the specimen \\
\hline 12 & $\mathrm{~T} 10$ & $12 \mathrm{mesh} \phi 3 \mathrm{~mm}$ & $3 \%$ & Meshes distributed in the whole specimen \\
\hline
\end{tabular}

\section{Finite Element Model}

The readymade software package AUTODYN-3D was used in developing the finite element model of the tested concrete panels. It is also used to simulate the penetration process of projectiles into different concrete targets. The concrete target and the projectile are modeled as Lagrangian meshes in all models, while the reinforcing steel meshes were modeled as beam elements in ferrocement models. All parts were symmetric on $\underline{X=0}$ planes to reduce the size of the computational domain. The geometry and meshes of the projectile, concrete target and steel meshes are described below. The material models depend on the physical materials. Table 2 illustrates the basic information specified for each material. Typically four basic types of information are specified for each material:

1. Equation of State: Pressure as function of density and internal energy.

2. Strength model: Strength model, which defines the yield surface.

3. Failure model: Failure model prescribing when the material no longer has strength

4. Erosion model: Erosion criteria. When a material is eroded, it is transformed from solid element to a free mass node (Lagrange only). 
Table 2. Basic information specified for each material.

\begin{tabular}{c|c|c|c}
\hline \hline & Projectile & Concrete Panels & Reinforcing Steel \\
\hline Equation of State & Linear & P-Alpha & Linear equation \\
\hline Strength model & Johnson Cook & RHT & Piecewise JC \\
\hline Failure model & Johnson Cook & RHT & None \\
\hline Erosion model & $\begin{array}{c}\text { Instantaneous } \\
\text { geometrical strain }\end{array}$ & $\begin{array}{c}\text { Instantaneous } \\
\text { geometrical strain }\end{array}$ & $\begin{array}{c}\text { Instantaneous } \\
\text { geometrical strain }\end{array}$ \\
\hline \hline
\end{tabular}

\subsection{Projectile}

The geometry of the projectile part was defined in all models using unstructured Lagrangian mesh with Four-node quadrilateral elements. Due to the symmetric conditions, the projectile geometry, which is $23 \mathrm{~mm}$ diameter and $64 \mathrm{~mm}$ length is modeled as a half cylinder, it is divided to 704 element. The main material parameter for steel used in projectile was chosen from the AUTODYN material library (STEEL 4340) and modified according to the values obtained from material data sheet and listed in Table3. Fig.1: shows the geometry and mesh description for the projectile part.

Table 3. Mechanical properties of the 23 AP projectile materials.

\begin{tabular}{c|c|c|c}
\hline \hline $\begin{array}{c}\text { Brinell hardness } \\
\text { number }(\mathrm{HB})\end{array}$ & $\begin{array}{c}\text { Yield strength } \\
(\mathrm{MPa})\end{array}$ & $\begin{array}{c}\text { Ultimate strength } \\
(\mathrm{MPa})\end{array}$ & $\begin{array}{c}\text { Strain to fracture } \\
(\%)\end{array}$ \\
\hline 475 & 1726 & 1900 & 7 \\
\hline \hline
\end{tabular}

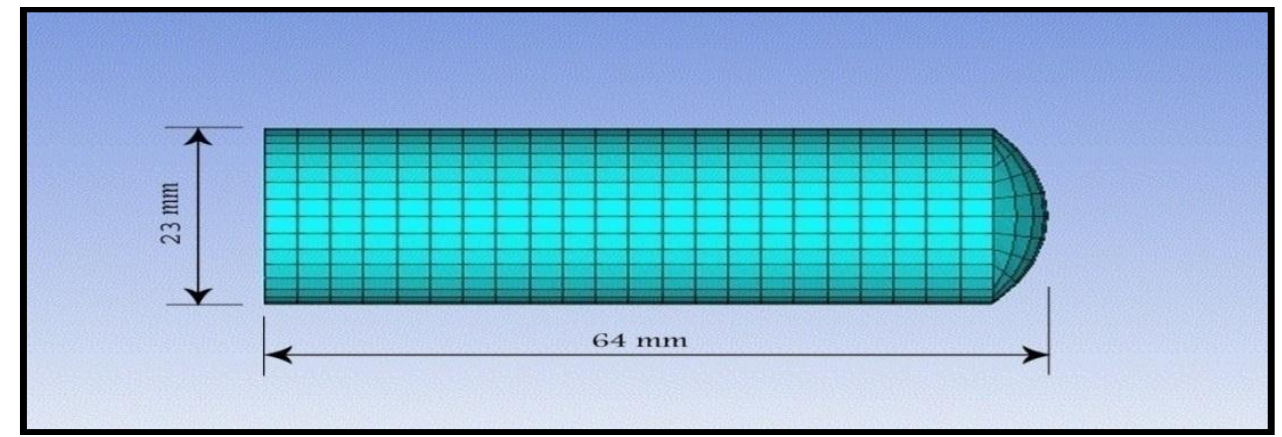

Fig. 1 Dimensions and meshing of the projectile.

\subsection{Target Reinforced Concrete Panels}

The reinforced concrete panels consist of the concrete target and steel mesh layers. The concrete target is defined using unstructured Lagrangian mesh with Four-node quadrilateral elements. Due to the symmetric conditions, the geometry of each part which was square 550 $\mathrm{mm}$ side length and $300 \mathrm{~mm}$ thickness was modeled as half box. It was divided into 243000 part. Zoning technique was used to refine the meshes in critical region; the element size was 2 $\mathrm{X} 2 \mathrm{X} 5 \mathrm{~mm}$ in the impact (maximum stress) region. The material for concrete was chosen from the AUTODYN material library (Concrete $35 \mathrm{MPa}$ ) and modified according to the values listed in Table 4. [11]. Figure (2) shows the geometry and meshing of the model. 
The dimension of expanded steel mesh used in all analytical tests for (T1 to T10) is $550 \times 550$ $\mathrm{mm}$. In case of using steel mesh of $3 \mathrm{~mm}$ thickness, the opening size is $16 \mathrm{~mm}$ x $38 \mathrm{~mm}$ and in case of using steel mesh of $5 \mathrm{~mm}$ thickness the opening size is $30 \mathrm{~mm}$ x $90 \mathrm{~mm}$. The number of steel layers that represent each reinforcement ratio and its position are as indicated in Table 1. The material model used to represent the steel mesh material was Johnson Cook strength model with material type chosen from the AUTODYN library (STEEL 1006) and modified as listed in Table 5. [11]. Fig.3 illustrate sample of the test for numerical test T8.

The concrete cover for the first steel layer is $2 \mathrm{~cm}$ from panel rear/front face. The beam elements used to model the steel meshes are connected to the correspondent concrete nodes.

Table 4 Mechanical properties of concrete.

\begin{tabular}{c|c|c|c|c}
\hline \hline Property & Density $\left(\mathrm{kg} / \mathrm{m}^{3}\right)$ & $\begin{array}{c}\text { Compressive } \\
\text { strength }(\mathrm{MPa})\end{array}$ & $\begin{array}{c}\text { Tensile strength } \\
(\mathrm{MPa})\end{array}$ & $\begin{array}{c}\text { Modulus of } \\
\text { elasticity }(\mathrm{GPa})\end{array}$ \\
\hline value & 2360 & 70 & 3.1 & 29 \\
\hline \hline
\end{tabular}

Table 5 Mechanical properties of steel mesh.

\begin{tabular}{c|c|c|c|c}
\hline \hline Property & Density $\left(\mathrm{kg} / \mathrm{m}^{3}\right)$ & $\begin{array}{c}\text { Yield strength } \\
(\mathrm{MPa})\end{array}$ & $\begin{array}{c}\text { Ultimate } \\
\text { strength }(\mathrm{MPa})\end{array}$ & $\begin{array}{c}\text { Modulus of } \\
\text { elasticity }(\mathrm{GPa})\end{array}$ \\
\hline value & 7850 & 250 & 460 & 210 \\
\hline \hline
\end{tabular}

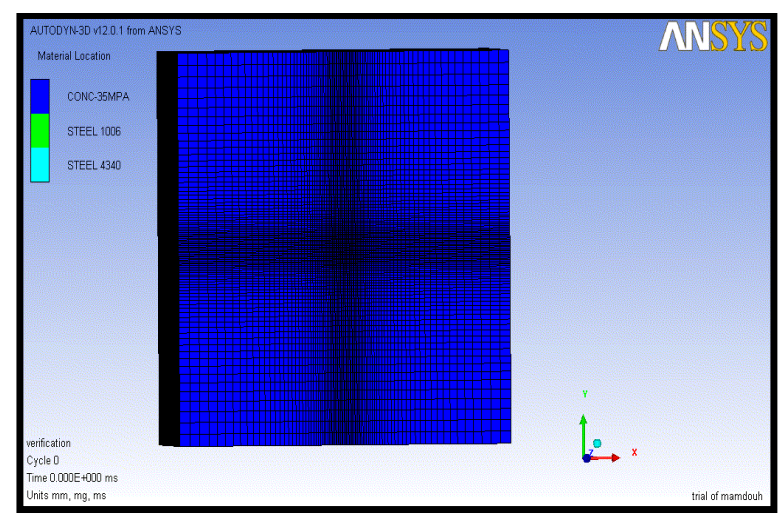

Fig. 2 Geometry and meshing of the concrete panels.

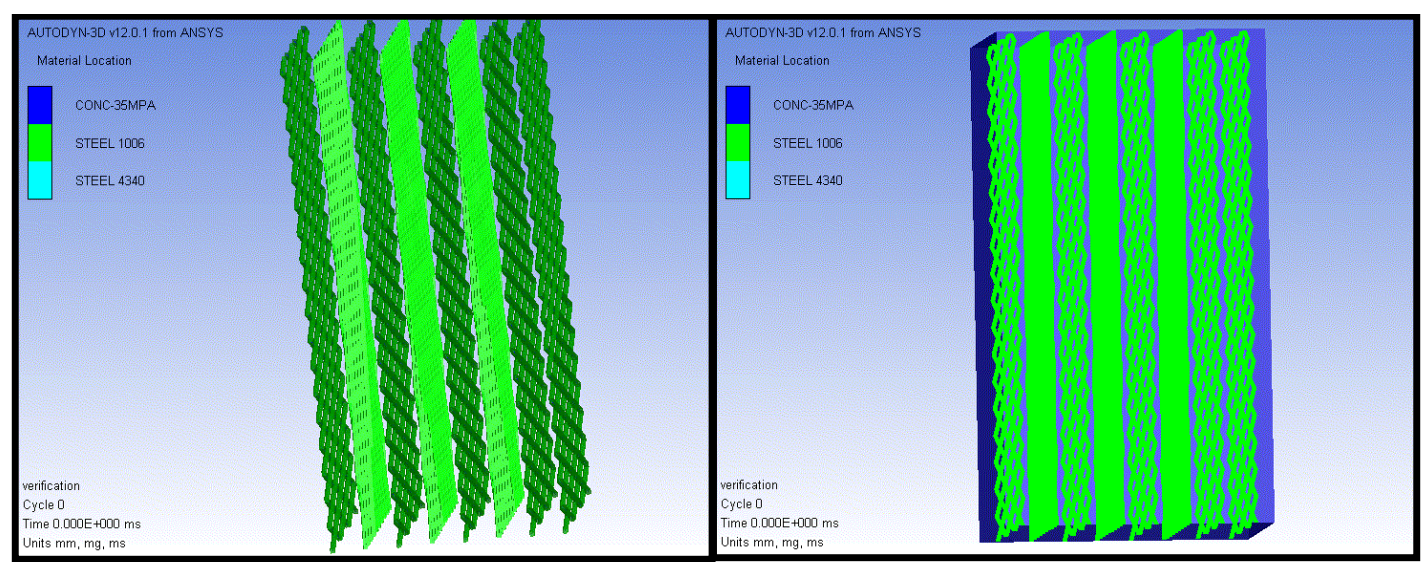

Fig. 3 Steel layers distribution in (T8). 


\subsection{Initial and Boundary Conditions}

The initial condition for projectile velocity used in numerical simulation in all analytical tests is equal to $990 \mathrm{~m} / \mathrm{sec}$, directed in the negative $\mathrm{Z}$ direction as shown in Fig. 4 .

The boundary conditions of the nodes located on the rear face of the concrete panels are defined as constant velocity in $\mathrm{Z}$ direction $(\mathrm{Vz}=0)$. While the boundary conditions of the nodes located on the lower face of the concrete panels are defined as constant velocity in $\mathrm{Y}$ direction $(\mathrm{Vy}=0)$, Fig.5: illustrate the boundary conditions on the concrete panel surface.

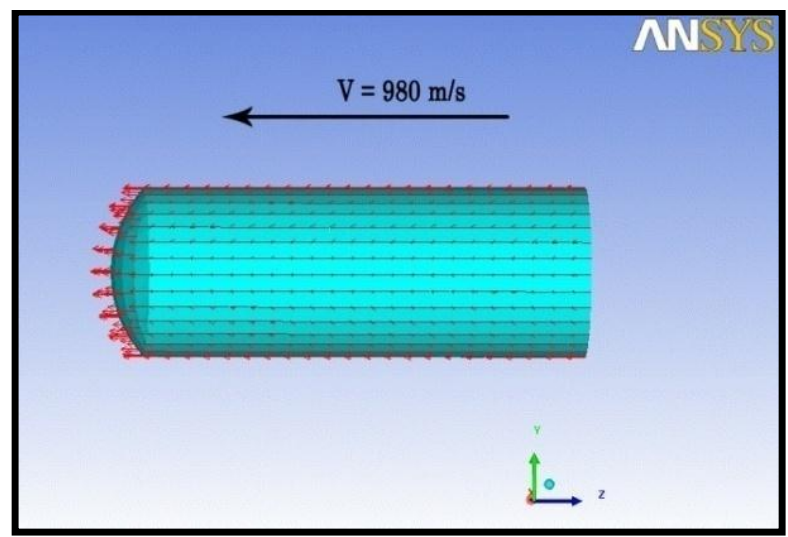

Fig. 4 Initial condition of projectile.

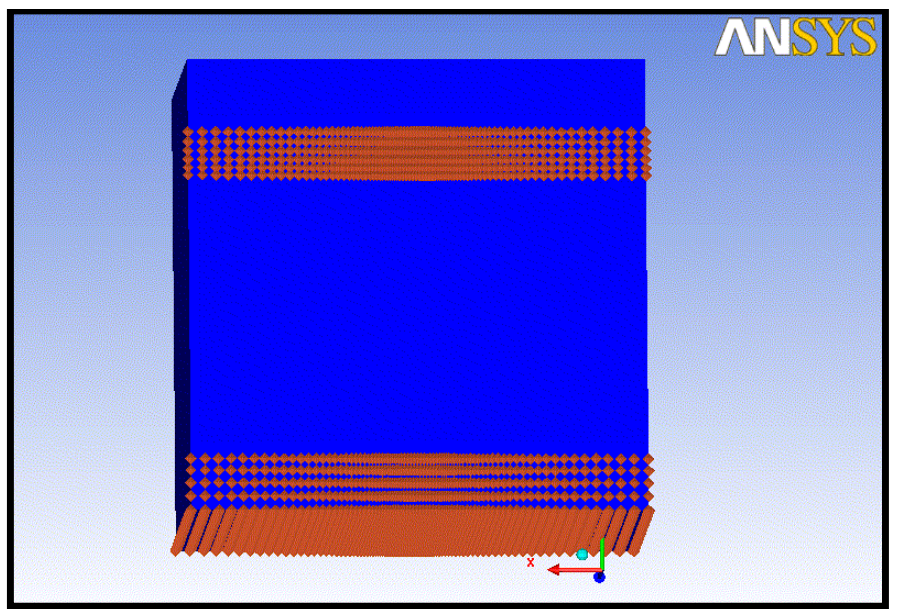

Fig. 5 Boundary conditions of targeted concrete panel.

\section{Model Interaction}

Two types of interaction may be defined in AUTODYN software [11]: Lagrange/Lagrange and Euler/ Lagrange interaction. In current numerical simulation, impact slide surface was between two Lagrange subgrids, so the interaction between these sub-grids is specified as Lagrange/Lagrange interaction.

Projectile - concrete interaction was achieved using the TRAJECTORY interaction logic. The Trajectory contact algorithm is implemented for all unstructured Lagrangian solvers. In the trajectory method a contacting node is pushed back to the true contact position during the computational cycle. In the trajectory algorithm the PENALITY method is chosen where, if a contact event is detected, a local penalty force is calculated to push the node back to the face. 
Equal and opposite forces are calculated on the nodes of the face in order to conserve linear and angular momentum. The applied penalty force will push the node back towards the true contact position during the cycle. However, it will take several cycles to satisfy the contact condition. Kinetic energy is not necessarily conserved. The conservation of energy can be tracked using the energy time history.

\section{Results and Discussion}

The results of the aforementioned parametric study represented by the twelve numerical simulation tests listed in Table 1. are discussed here after. The relative comparison of the output of these parametric studies is based on three main measuring parameters: the penetration depth, the front face damaged area and the rear face damaged area. The penetration resistance of the proposed twelve panels is mainly dependent on the values of these measured parameters.

Tables $6,7 \& 8$ contain the results of the numerical simulation tests. The penetration depth and stopping time values considered as the main indices to reflect the relative penetration resistance of the tested panels. A list of figures: Fig. 6 to Fig. 11 represent sample of the results of the numerically tested panels that can be used to illustrated the penetration depth and penetration - time history for each.

Table. 6. Penetration Resistance Results of Numerical Simulation Tests.

\begin{tabular}{c|c|c|c|c}
\hline \hline No. & Model & $\begin{array}{c}\text { Reinforcement } \\
\text { ratio }\end{array}$ & $\begin{array}{c}\text { Penetration } \\
\text { Depth }(\mathrm{cm})\end{array}$ & $\begin{array}{c}\text { Stopping Time of } \\
\text { Penetration }(\mathrm{ms})\end{array}$ \\
\hline 1 & $\mathrm{~T} 1$ & $0.37 \%$ & 23 & 1.2 \\
\hline 2 & $\mathrm{~T} 2$ & $0.56 \%$ & 22.6 & 1.15 \\
\hline 3 & $\mathrm{~T} 3$ & $0.75 \%$ & 22.5 & 1 \\
\hline 4 & $\mathrm{~T} 4$ & $1.5 \%$ & 22.4 & 1.1 \\
\hline 5 & $\mathrm{~T} 5$ & $2.25 \%$ & 22.2 & 1.25 \\
\hline 6 & $\mathrm{~T} 6$ & $3 \%$ & 22 & 1.1 \\
\hline 7 & $\mathrm{~T} 7$ & $1.5 \%$ & 21.2 & 0.8 \\
\hline 8 & $\mathrm{TS} 7$ & $1.5 \%$ & 20.5 & 0.8 \\
\hline 9 & $\mathrm{~T} 8$ & $3 \%$ & 19.35 & 1 \\
\hline 10 & $\mathrm{~T} 58$ & $3 \%$ & 21 & 1 \\
\hline 11 & $\mathrm{~T} 9$ & $1.5 \%$ & 22.16 & 0.8 \\
\hline 12 & $\mathrm{~T} 10$ & $3 \%$ & 20.69 & 1.1 \\
\hline \hline
\end{tabular}

\subsection{Effect of reinforcement ratio on penetration resistance}

The relationship between the reinforcement ratio and the penetration depth is the first parametric study carried out as part of the numerical simulation. Based on the literature review, there is a dispute over the optimal value and the position of the reinforcement. Accordingly many values of reinforcement ratio were considered in the numerical simulations as it has increased sequentially from $(0.37 \%)$ in (T1) to (3\%) in (T6) as listed in Table 1 . The reinforcement is placed in the tension side at the rear face using the same mesh size $(5 \mathrm{~mm})$. As it can be seen from Table 6, the reinforcement ratio has insignificant influence on the improvement of the penetration resistance of the reinforced concrete panels. This finding is firstly attributed to the position of the reinforcement as it is concentrated at the rear face. The 
probable explanation for this result is: during the penetration process, the compressive strength of the concrete panel represents the main parameter that can influence the penetration resistance.

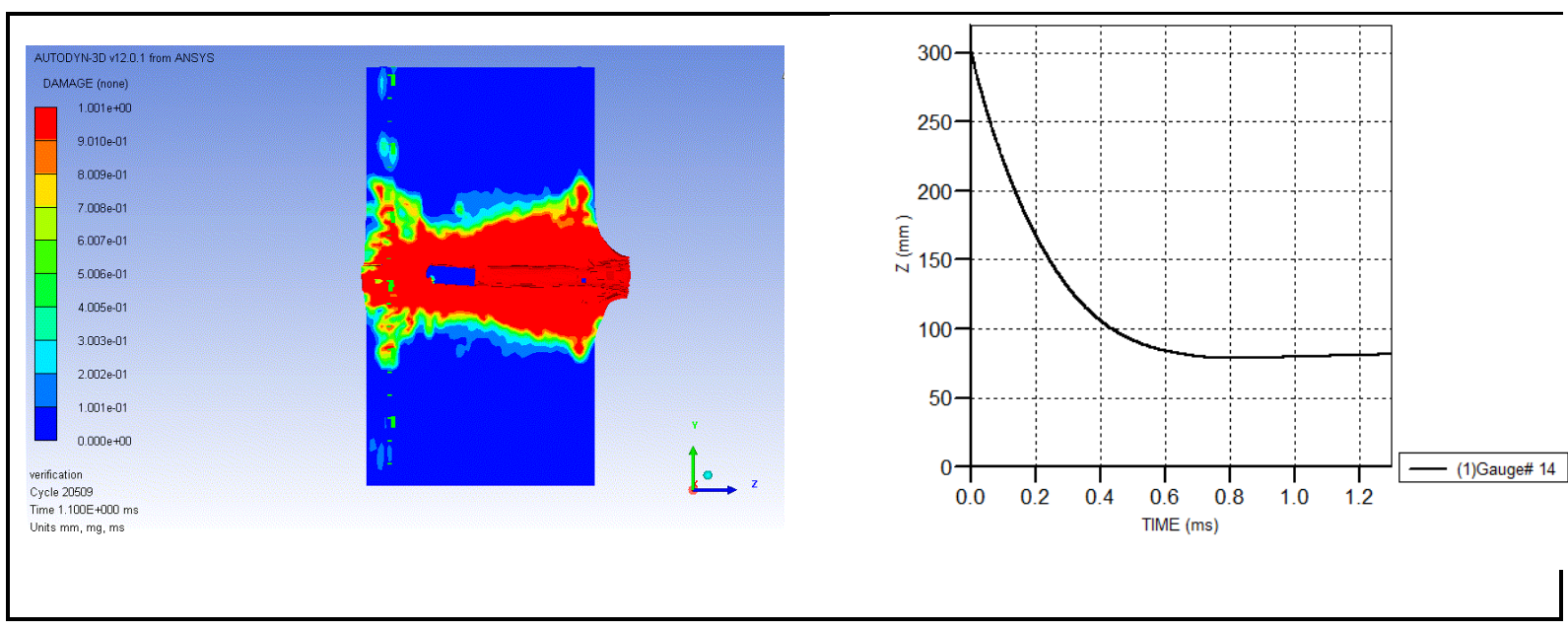

Fig. 6 Penetration depth and Penetration-time history for test T4

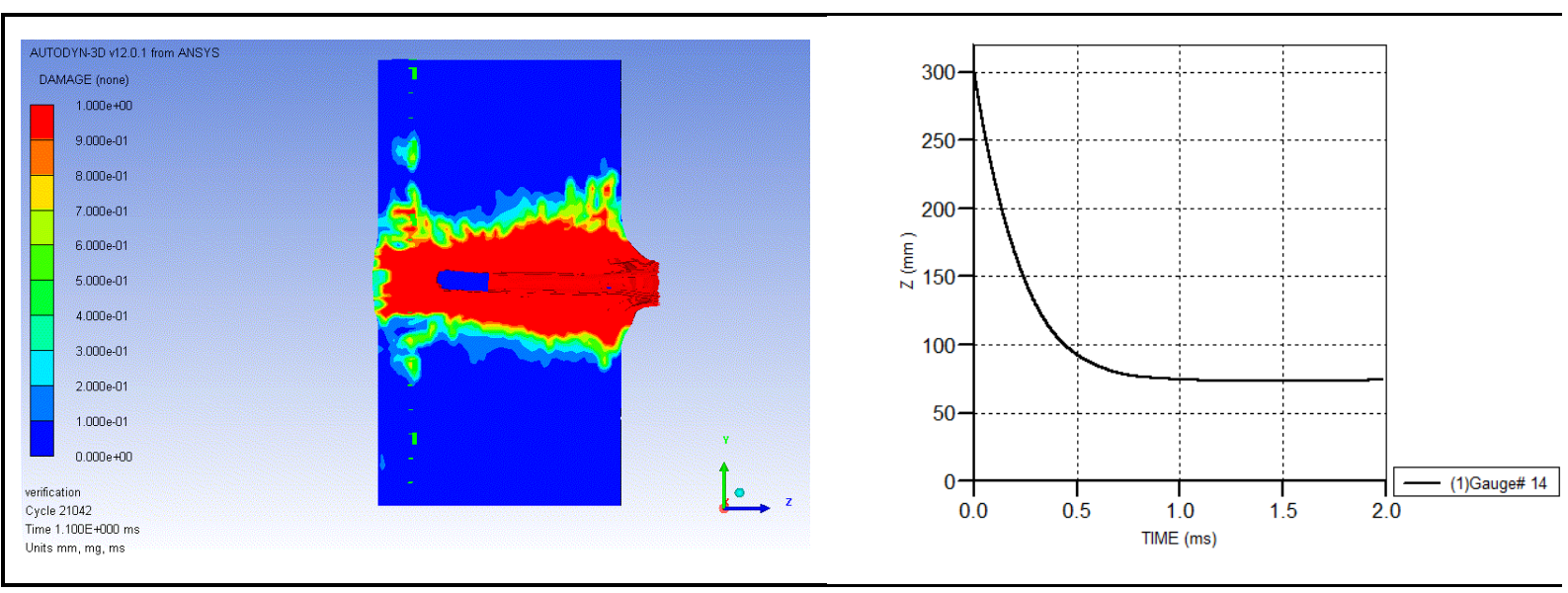

Fig. 7 Penetration depth and penetration-time history for test T6

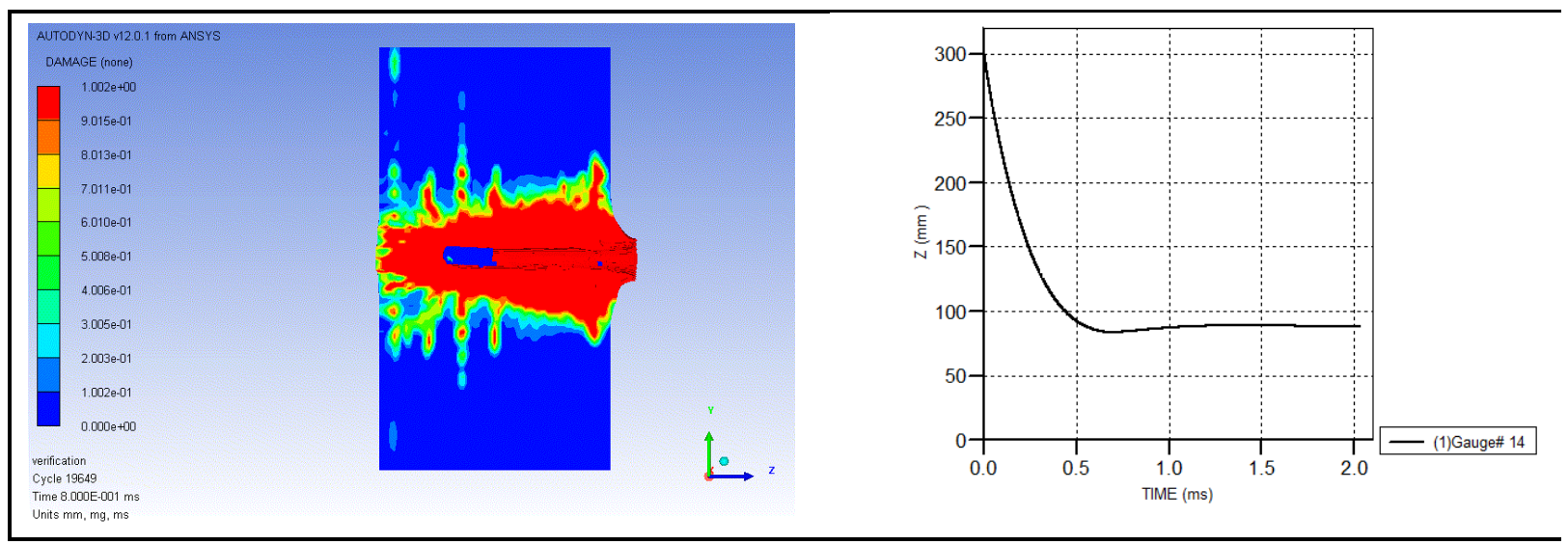

Fig. 8 Penetration depth and penetration-time history for test T7 


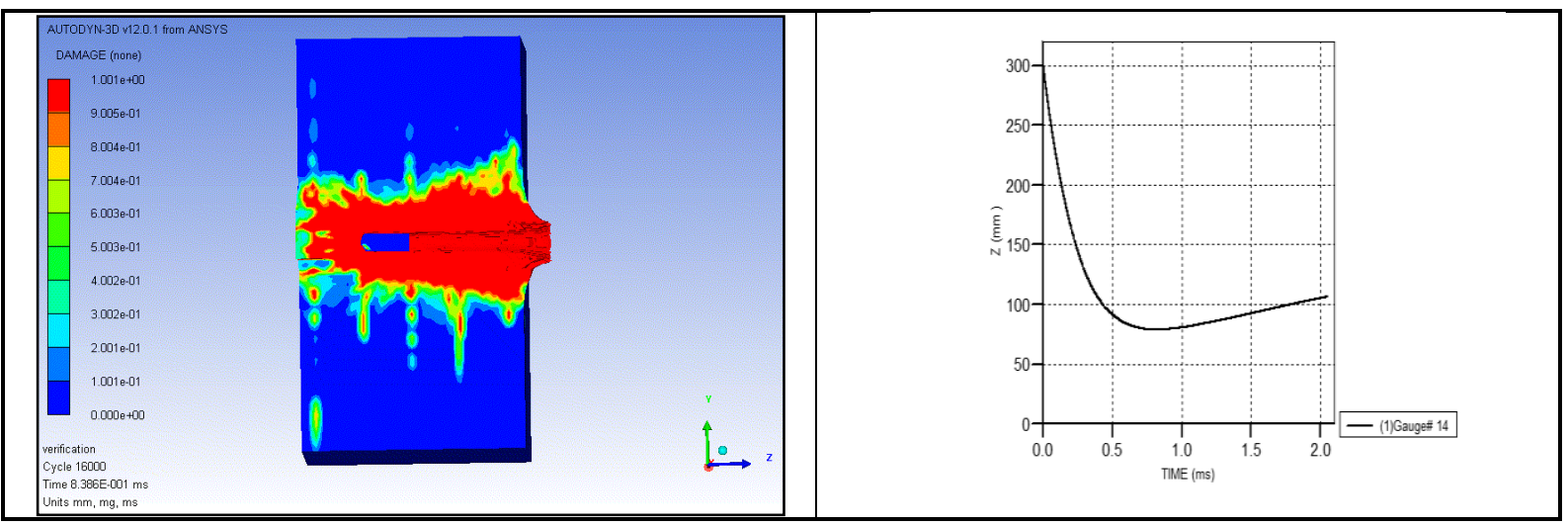

Fig. 9 Penetration depth and Penetration-time history for test TS7

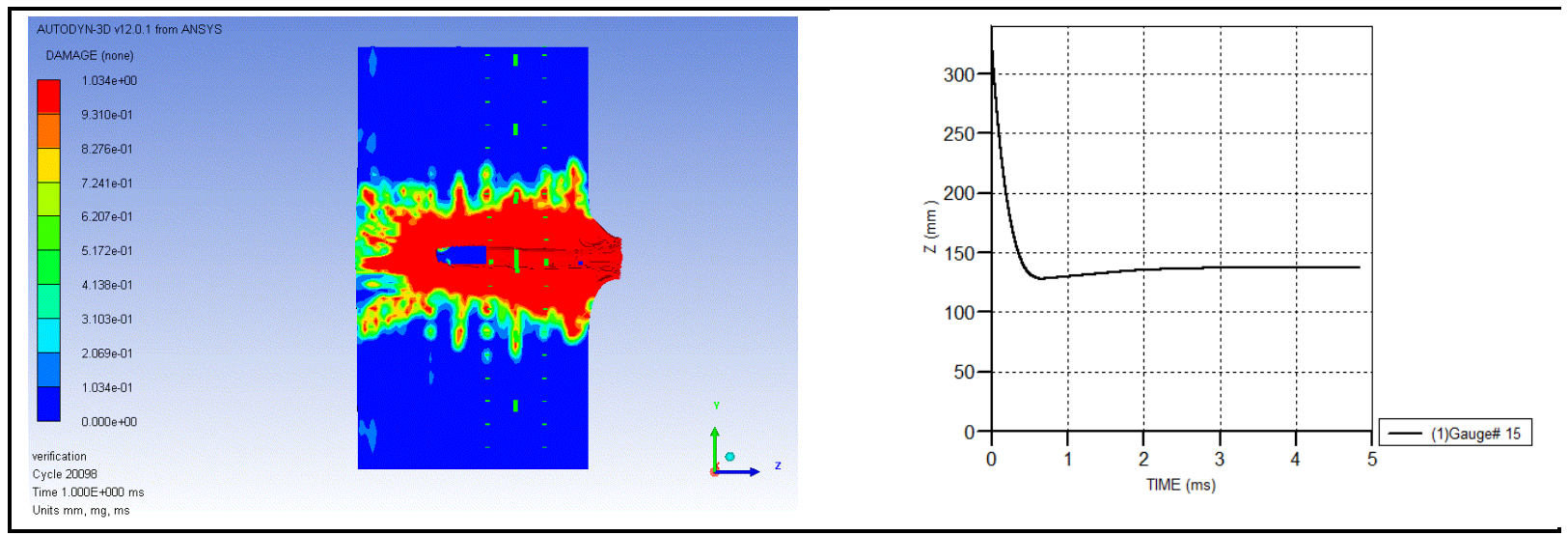

Fig. 10 Penetration depth and Penetration-time history for test T8

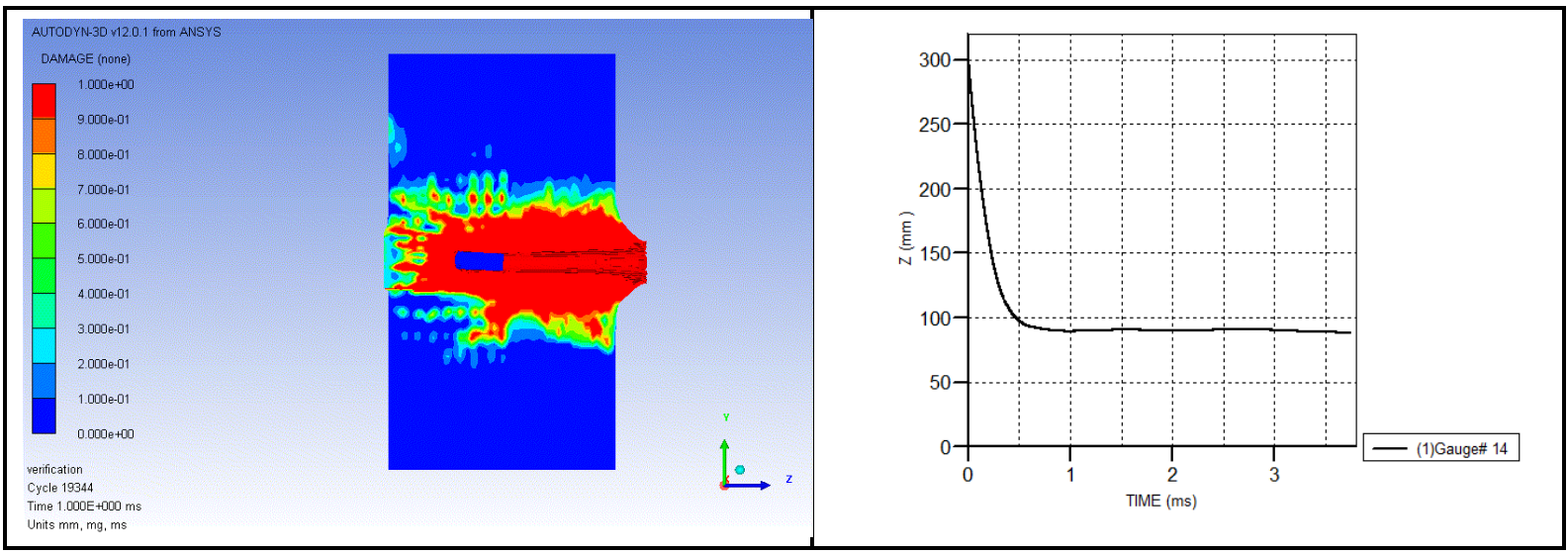

Fig. 11: Penetration depth and penetration-time history for test TS8

\subsection{Effect of reinforcement position and distribution on penetration resistance}

Based on the simulation results ( $\mathrm{T} 1$ to $\mathrm{T} 6$ ), it was crucial to consider the reinforcement distribution in the concrete panel as an important parameter that may influence the penetration resistance. Consequently, during this step of the numerical simulation, two reinforcement ratios $(1.5 \%$ and $3 \%)$ were selected to examine the influence of that parameter. In simulation test (T7 and TS7), the reinforcement ratio $1.5 \%$ is distributed equally spaced through the rear half and whole depth respectively. Also, in simulation test (T8 and TS8), the reinforcement ratio $3 \%$ is distributed equally spaced through the rear half and whole depth respectively. The results of simulation (T7 and TS7) are compared to its counterpart (T4) and the results of simulation (T8 and TS8) are compared to its counterpart (T6). Table 7 summarizes the results, 
from which it can be concluded that distribution of the reinforcement through the rear half has a remarkable influence on the penetration depth; moreover it is more efficient to distribute the reinforcement through the whole depth of the concrete panel. This result can be attributed to the homogenous distribution of the interaction between reinforcement and compressive strength of concrete through the depth.

\subsection{Effect of Steel Mesh Size on Penetration Resistance}

One of the parameters studied during this part of the research is the effect of the wire mesh size on the penetration resistance of the concrete panels. Two numerical simulation tests were carried out to satisfy the aforementioned objective. The numerical simulation tests that proved the best penetration resistance in the parametric study, (T7 and T8) are used as references in this test. Both tests (T9 and T10) have the same reinforcement ratio for their references (T7 and T8) respectively. As in tests (T9 and T10) 3mm wire mesh is used instead of 5mm wire mesh used in (T7 and T8). The results of the penetration depth acquired in (T9 and T10) is listed in Table 8 compared to its correspondence (T7 and T8) respectively. The results showed a considerable decrease in the penetration depth for the bigger mesh size for the same reinforcement ratio.

Table 7 Relation between reinforcement and penetration depth.

\begin{tabular}{c|c|c|c|c|c}
\hline \hline No. & Test & $\begin{array}{c}\text { Mesh } \\
\text { thickness }\end{array}$ & Reinforcement Position & $\begin{array}{c}\text { Reinforcement } \\
\text { Ratio }\end{array}$ & $\begin{array}{c}\text { Penetration } \\
\text { depth }\end{array}$ \\
\hline 1 & T4 & $5 \mathrm{~mm}$ & Rear face & $1.5 \%$ & $22.4 \mathrm{~cm}$ \\
\hline 2 & $\mathrm{~T} 7$ & $5 \mathrm{~mm}$ & $\begin{array}{c}\text { Equally distributed in the rear half } \\
\text { of the specimen }\end{array}$ & $1.5 \%$ & $21.2 \mathrm{~cm}$ \\
\hline 3 & $\mathrm{TS} 7$ & $5 \mathrm{~mm}$ & $\begin{array}{r}\text { Equally distributed in the whole } \\
\text { specimen }\end{array}$ & $1.5 \%$ & $20.5 \mathrm{~cm}$ \\
\hline 4 & T6 & $5 \mathrm{~mm}$ & Rear face & $3 \%$ & $22 \mathrm{~cm}$ \\
\hline 5 & $\mathrm{TS} 8$ & $5 \mathrm{~mm}$ & $\begin{array}{r}\text { Equally distributed in the rear half } \\
\text { of the specimen }\end{array}$ & $3 \%$ & $21 \mathrm{~cm}$ \\
\hline 6 & $\mathrm{~T} 8$ & $5 \mathrm{~mm}$ & $\begin{array}{r}\text { Equally distributed in the whole } \\
\text { specimen }\end{array}$ & $3 \%$ & $19.35 \mathrm{~cm}$ \\
\hline
\end{tabular}

Table 8 Relation between mesh size and penetration depth.

\begin{tabular}{c|c|c|c|c|c}
\hline \hline No. & Test & $\begin{array}{c}\text { No. of Steel } \\
\text { mesh and size } \\
(\mathrm{mm})\end{array}$ & Reinforcement Position & $\begin{array}{c}\text { Reinforcement } \\
\text { Ratio }\end{array}$ & $\begin{array}{c}\text { Penetration } \\
\text { Depth }(\mathrm{cm})\end{array}$ \\
\hline 1 & $\mathrm{~T} 7$ & 4 mesh $\phi 5 \mathrm{~mm}$ & $\begin{array}{c}\text { Equally distributed in the rear } \\
\text { half of the specimen }\end{array}$ & $1.5 \%$ & 21.2 \\
\hline 2 & $\mathrm{~T} 9$ & 6 mesh $\phi 3 \mathrm{~mm}$ & $\begin{array}{c}\text { Equally distributed in rear half of } \\
\text { the specimen }\end{array}$ & $1.5 \%$ & 22.16 \\
\hline 3 & $\mathrm{~T} 8$ & 8 mesh $\phi 5 \mathrm{~mm}$ & $\begin{array}{r}\text { Equally distributed in the whole } \\
\text { specimen }\end{array}$ & $3 \%$ & 19.35 \\
\hline 4 & $\mathrm{~T} 10$ & 12 mesh $\phi 3 \mathrm{~mm}$ & $\begin{array}{r}\text { Meshes distributed in the whole } \\
\text { specimen }\end{array}$ & $3 \%$ & 20.69 \\
\hline \hline
\end{tabular}




\section{Conclusions}

From the previous models it is concluded that increasing the percentage of reinforcement has a slight influence on penetration depth but it decreases the size of damage in the front and rear face. Also, distributing the steel meshes on the specimen has a relatively positive influence on the penetration resistance. Increasing the thickness of reinforcement mesh increases the penetration resistance of the tested concrete specimen.

\section{References}

[1] Gold, V.M., "Analysis of the penetration resistance of concrete", U.S. army armamant research, 1997.

[2] Jason T. and Gomeza, A.S., "Multiple impact penetration of semi-infinite concrete". International Journal of Impact Engineering, 2001. 25: p. 965-979.

[3] Forrestal MJ, L.V., "Penetration into soil targets", international Journal of impact engineering, 1992. 12: p. 427-44.

[4] J. Buchar , J.V., S. Rolc and M. Lazar, "Response of concrete to the impact of fragments simulating projectiles", $20^{\text {th }}$ International Symposium on Ballistics, ORLANDO, 2002.

[5] Avraham N. and Dancygier, D.Z.Y., Chanoch Jaegermann, "Response of high performance concrete plates to impact of non-deforming projectiles", International Journal of Impact Engineering, 2007. 34: p. 1768-1779.

[6] Murtiadi, S., "Behavior of high strength concrete plates under impact loading", M.Sc. thesis, faculty of engineering and applied science, memorial university of newfoundland, canada, 1999.

[7] YANKELEVSKY, A.N.D.a.D.Z., "High strength concrete response to hard projectile impact”, International journal of impact engineering, 1996. 18(6): p. 583-599.

[8] 549, A.c., "State-of-the-Art Report on Ferrocement", ACI 549R-97, 1997. ACI, Detroit (p.26).

[9] Zhang M. H., L.L., and Paramasivam P., "Flexural toughness and impact resistance of steel-fibre-reinforced lightweight concrete". Magazine of Concrete Research, 2004. 56(5): p. 251-262.

[10] Abdullah, K.T., Koshiro N., and Shingo H., "Behavior of Ferrocement Subjected to Missile Impact", Transactions of the 17th International Conference on Structural Mechanics in Reactor Technology, Prague, Czech Republic, 2003.

[11] Dynamics, A.E.S.f.N.-1., AUTODYN Electronic Document Library. Multiversions, Century Dynamics Inc., 2005.

[12] X.W. Chena , X.L.L., F.L. Huang , H.J. Wu , Y.Z. Chen, "Normal perforation of reinforced concrete target by rigid projectile". International Journal of Impact Engineering, 2008. 35: p. 1119-1129. 